\title{
ASSESSING ANTI-TNF TROUGH LEVELS AND ITS APPLICABILITY IN DAILY PRACTICE IN SPONDYLOARTHRITIS PATIENTS
}

\author{
Claudia Deaconu ${ }^{1}$, Daniela Opris ${ }^{1,2}$, Ruxandra Ionescu ${ }^{1,2}$ \\ ${ }^{1}$ Department of Rheumatology and Internal Medicine, Sfanta Maria Clinical Hospital, Bucharest \\ ${ }^{2}$ Carol Davila University of Medicine and Pharmacy, Bucharest
}

\begin{abstract}
Objective. The purpose of the present study was to assess the relevance of therapeutic drug monitoring in spondyloarthritis patients, by determining drug serum levels and anti-drug antibodies and estimating cut-off values for three TNF inhibitors.

Methods. Over one year, we enrolled 100 patients with $\mathrm{SpA}$, under consequent treatment with adalimumab (ADL), etanercept (ETA) or infliximab (IFX). Demographic, clinical (BASDAI, ASDAS) and laboratory (ESR, CRP) data was collected together with drug serum level and anti-drug antibodies using the ELISA technique. The statistical analysis was performed using the SPSS software, version 20.0 with the aid of Student t-test, Spearman and Pearson tests.

Results. Out of the study cohort, $35 \%$ were on ADL, $33 \%$ on IFX, and $32 \%$ under ETA treatment. Undetectable drug levels correlated to the presence of anti-drug antibodies and to disease activity scores. There were no identified anti-ETA antibodies. For this study lot trough levels are estimated between 2 and $4 \mu \mathrm{g} / \mathrm{mL}$ for an ASDAS-CRP under 2.1.

Conclusion. Serum drug level measurement and anti-drug antibody detection can be used as a completion to a clinician's tools in assessing disease activity, leading to an optimal and personalized manner of patient management.
\end{abstract}

Keywords: spondyloarthritis, anti-TNF therapy, drug serum level, through level, personalized medicine

\author{
Abbreviations \\ IFX - infliximab \\ ADL - adalimumab \\ ETA - etanercept \\ BASDAI - Bath Ankylosing Spondylitis Disease Activity Index \\ ASDAS - Ankylosing Spondylitis Disease Activity Score \\ TNF - tumor necrosis factor
}

\section{INTRODUCTION AND OBJECTIVES}

In spite the heterogeneous clinical presentation of spondyloarthritis (SpA) spectrum affections, they share the same therapeutical options. Introducing anti-TNF (tumor necrosis factor) agents as second line treatment has revolutionized the outcome of these patients (1). However, setbacks such as loss or lack of response, side effect occurrence or high costs have constantly challenged clinicians.

Following the rheumatoid arthritis "model" (2-5) and recent trend of personalized medicine, latest studies propose therapeutic drug monitoring (TDM) in SpA patients $(6,7)$. This consists of drug level dos-
SpA - spondyloarthritis

NSAID - non-steroidal anti-inflammatory drugs

ELISA - enzyme linked immunosorbent assay

ESR - erythrocyte sedimentation rate

$\mathrm{CRP}-\mathrm{C}$ reactive protein

ing and anti-drug antibodies detection that would help practitioners have a more realistic approach face to biological therapy.

Drug monitoring plays a major role in detecting non-responder patients and incriminating immunogenicity as responsible for treatment failure (8). Moreover, it can lead to correctly identifying patients who would benefit from dose augmentation, therapy spacing or switching to another agent.

Several studies suggested the clinical relevance of drug monitoring but there is still scarce data on valid therapeutic cut-off levels of substance $(4,9,10)$. What is the through level at which we can decide to 
adjust the therapeutic scheme? Would this personalized approach generate lower treatment costs?

Anti-drug antibodies are thought to block the active constituent of the TNF inhibitor or they can form immune complexes that are rapidly cleared from circulation, thus deteriorating the beneficial effects of these agents $(11,12)$. Detecting their presence should guide rheumatologists to a prompter and correctly motivated switch and avoid further administration of an inefficient biologic.

In addition to biologic therapy, patients with SpA can use non-steroidal anti-inflammatory drugs (NSAIDs), whether it is for symptomatic use or for their allegedly aid in radiographic progression $(13,14)$.

The objective of this study was to evaluate the immunogenic profile and optimal serum concentrations of TNF inhibitors in patients with SpA undergoing treatment with adalimumab (ADL), etanercept (ETA) or infliximab (IFX) by measuring drug serum level and detecting anti-drug antibodies. We also aimed to assess to what extent immunogenicity is involved in switching biological therapies.

\section{MATERIALS AND METHODS}

\section{Patient recruitement}

We included a number of 100 patients diagnosed with SpA following the New York modified criteria or the 2009 ASAS classification criteria over a period of ten months. They were on continuous biological therapy with one the following three anti-TNFs: infliximab, adalimumab or etanercept for the past six months. Patients were recruited in the Department of Rheumatology of "Sfanta Maria" Clinical Hospital in Bucharest.

Patients with concomitant synthetic DMARD (disease modifying antirheumatic drug), delays in drug administration or infections while at hospital visits were excluded from the study lot.

Demographic data, clinical (mobility tests, disease activity scores BASDAI and ASDAS) and laboratory parameters (inflammatory markers ESR erythrocyte sedimentation rate and CRP C-reactive protein) were collected by the same physician.

The study was approved by the hospitals' Ethics Committee and all patients gave their written informed consent before proceeding with study procedures.

\section{Detection of serum drug level and anti-drug antibodies}

Serum drug levels and anti-drug antibodies were measured through a unique blood sampling using the enzyme linked immunosorbent assay (ELISA) method, with Progenika kits (Promonitor ADL ${ }^{\circledR}$, Promonitor IFX ${ }^{\circledR}$, Promonitor ETA ${ }^{\circledR}$, Promonitor anti-ADL ${ }^{\circledR}$, Promonitor anti-IFX ${ }^{\circledR}$, Promonitor anti-ETA ${ }^{\circledR}$ ).

ADA and ETA are determined using the sandwich ELISA technique that is based on measuring the color intensity of an added enzyme that develops in a spectrophotometer. The signal obtained is proportional to the amount of the drug in the patient sample. IFX is measured with capture ELISA, with a similar principle of detection. When interpreting results, the kit protocol states that a value of equal or under $0.035 \mu \mathrm{g} / \mathrm{mL}$ of IFX or ETA indicates that no substance is detected, while a level greater than $0.035 \mu \mathrm{g} / \mathrm{mL}$ signifies positivity for IFX or ETA detection; the same technique applies to ADL determination, using $0.024 \mu \mathrm{g} / \mathrm{mL}$ as bound limit.

Detection of anti-drug antibodies (ADA) uses bridging ELISA testing. The signal obtained in the spectrophotometer corresponds to the amount of anti-TNF $\alpha$ blocker antibody in the patient sample. Anti-ADL antibodies concentration of under 3.5 AU/ $\mathrm{mL}$, anti-ETA antibodies value of under 142.0AU/ $\mathrm{mL}$, and anti-IFX antibodies concentration below 2.0 AU/mL were considered negative.

These values were validated as cut-offs by the Promonitor kits after performing a statistical evaluation of patient samples in different rheumatic pathologies but they are not stated as therapeutical levels with proven clinical impact.

All blood samples were collected respecting the optimal collection time, which is immediately before drug administration.

\section{Statistical analysis}

The statistical analysis was performed with the aid of SPSS software, version 20.0, setting a significant $P$ value at 0.05 . Data was revealed as mean value \pm standard deviation (SD). Differences between groups were recorded with the aid of Student t-test, whereas Spearman and Pearson tests were used for correlations.

\section{RESULTS}

The study cohort consisted of 100 patients, $35 \%$ on ADL, $33 \%$ on IFX, and $32 \%$ under ETA treat- 
ment. Seventy-eight percent of patients were males and $93 \%$ had a positive HLA B27 antigen. The distribution of patients according to age groups showed that 21 patients were under 30,37 patients between 30 and 40 and 20 patients were aged between 40 and 50 . The rest of 22 patients were over 50 years of age.

The age distribution following biological treatment is shown below in Fig. 1.

The ADL-treated group comprised of 35 patients, $74 \%$ being of male gender with a mean age of 40 years old. Mean disease duration was 102 months. All patients in this group were HLA B27 positive.

Eighty-two percent of patients had detectable drug concentrations while $17 \%$ were ADL-negative. Among the first group, $86 \%$ had negative anti-drug antibodies and $14 \%$ were found positive for antibodies. Eighty-three percent of patients with no detectable serum drug had positive anti-ADL antibodies, while $17 \%$ had no anti-drug antibodies. Out of the study population, $25 \%$ had positive ADL-antibodies (Fig. 2).

All patients that had detectable ADL at sampling had a BASDAI score of under 6 , with a mean ADL serum value of $6.26 \pm 4.7 \mu \mathrm{g} / \mathrm{ml}$. Sixty-eight percent of patients with ADL level of over $4 \mu \mathrm{g} / \mathrm{ml}$ had a BASDAI lower than 2. Four patients in the study group had both detectable ADL active substance and anti-drug antibodies, suggesting a different pathogenic mechanism in the disease course (red scatters represented in Fig. 3).

Patients with no detectable serum ADL had a mean BASDAI value of 6.3. Similarly, ASDAS-ESR and ASDAS-CRP were higher in these patients $(\mathrm{P}<0.001)$.

With regard to drug serum level and anti-drug antibodies determination we observed notable differences between the two patient categories, as seen below in Fig. 4.

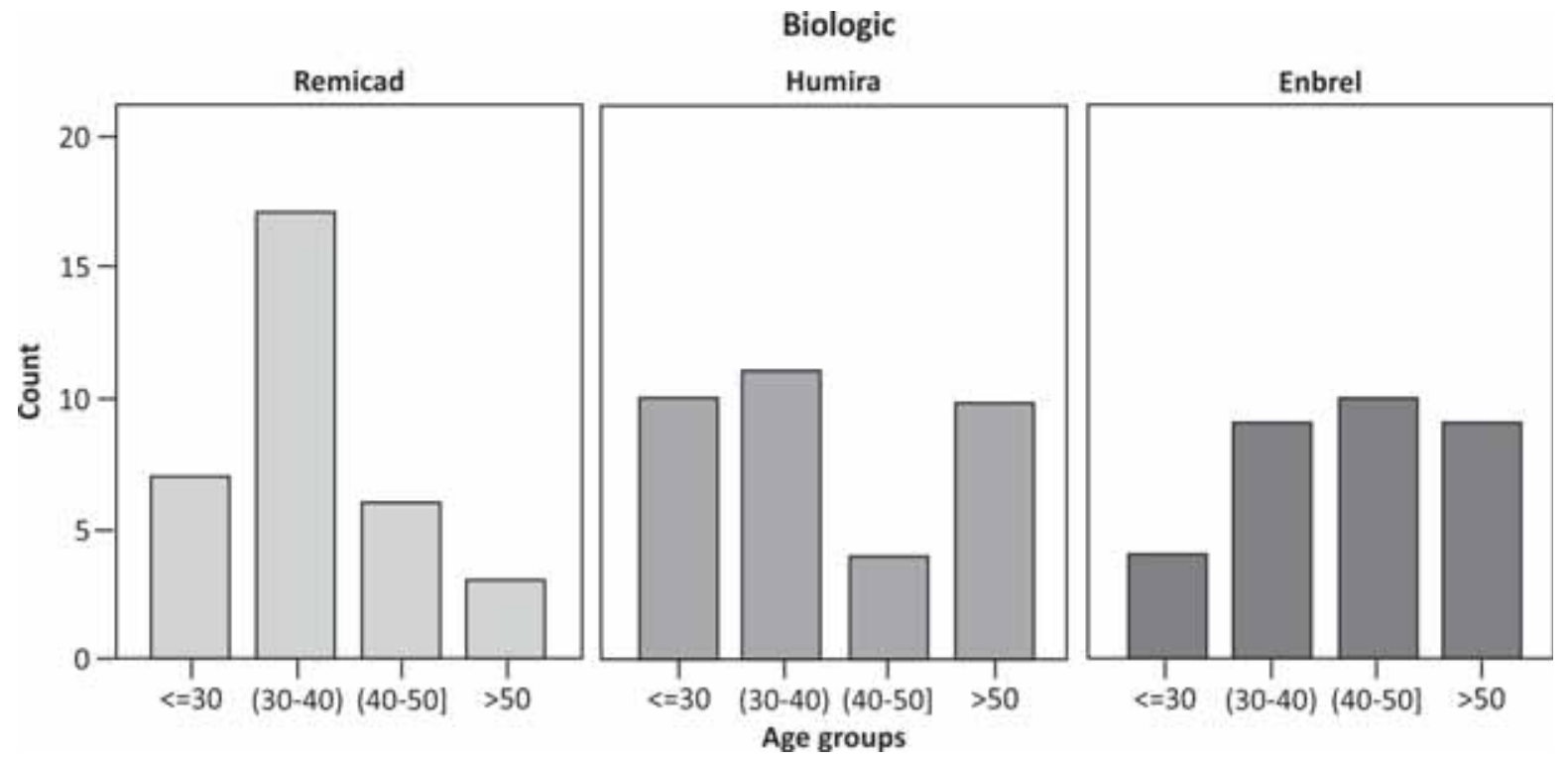

FIGURE 1. Biological therapy according to age group distribution



FIGURE 2. ADL detectable serum level and anti-ADL antibodies 

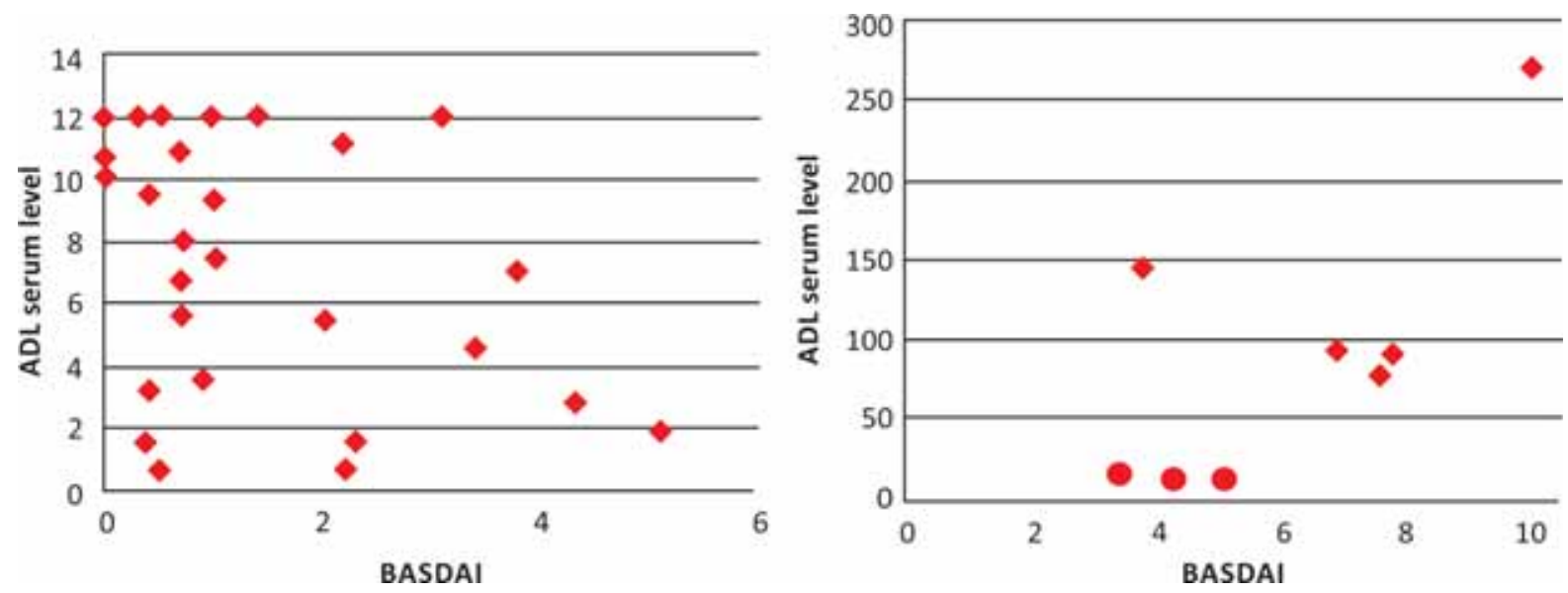

FIGURE 3. ADL serum level and anti-ADL antibodies when reported to BASDAI

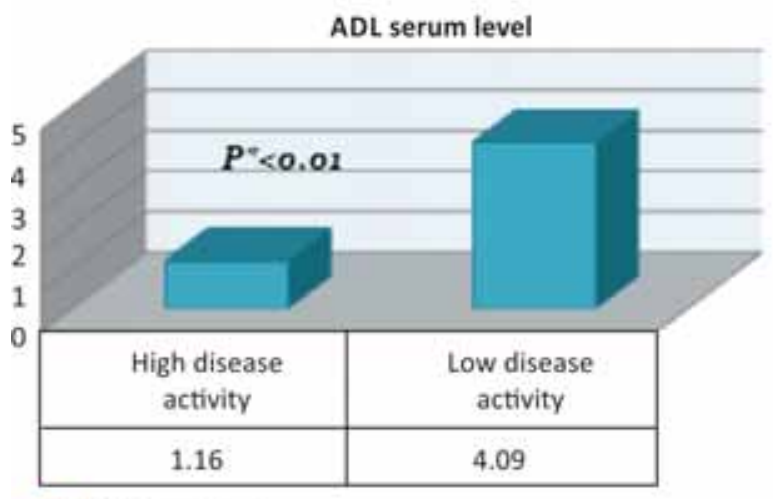

ADL serum level

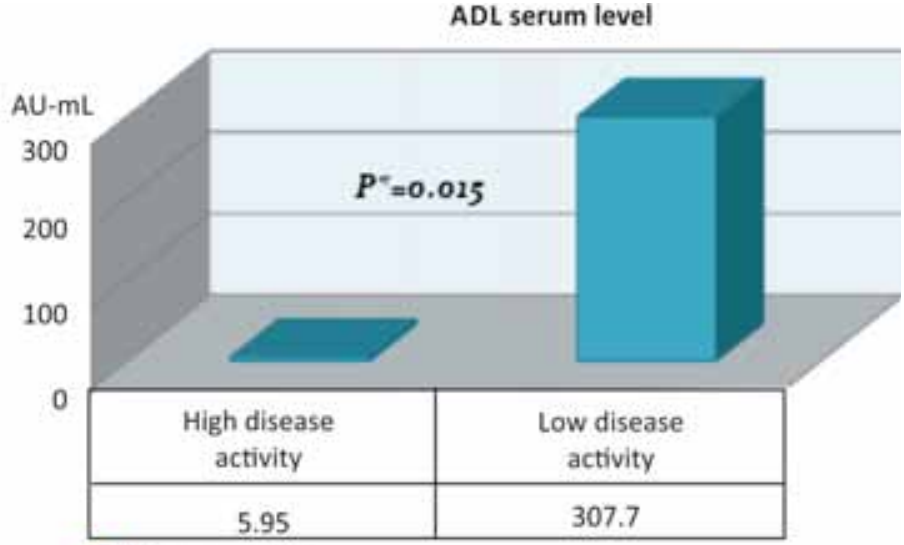

ADL serum level

FIGURE 4. Results in serum drug level and anti-drug antibodies determination in patients with high disease activity (BASDAI>4) versus patients with low disease activity (BASDAl<4)

When assesing ADL serum level we noted differences between patient categories, with lower detectable drug in patients with high disease activity according to ASDAS-CRP ( $\mathrm{P}=0.04$, Fig. 5).

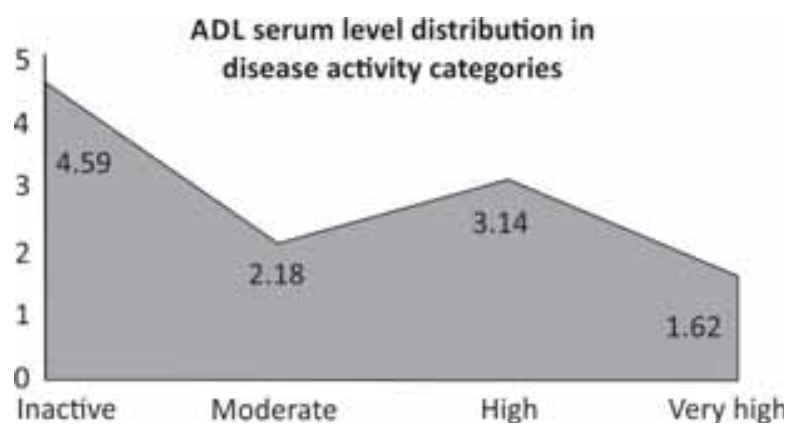

FIGURE 5. ADL serum level distribution in different disease activity categories divided through ASDAS-CRP

Regarding the ETA treated group, 69\% (22 patients) were males and $87 \%$ presented HLA B27 antigen positivity. The mean age was 44.3 years old \pm 11 , having a mean disease duration of 101 months (approx. 8.5 years $\pm 81 \mathrm{mo}$ ).

Out of the 32 patients, two had undetectable drug serum level. Without reaching statistical significance, mean values of disease scores and inflammatory markers were higher in the ETA-negative group. Differences in disease activity scores (BASDAI, ASDAS) and inflammatory markers between patients with detectable and undetectable ETA are shown in Table 1.

TABLE 1. Differences in disease activity between patients with detectable and undetectable ETA serum levels

\begin{tabular}{|l|c|c|c|}
\hline $\begin{array}{l}\text { Variable } \\
\text { (mean values } \\
\mathbf{\pm S D})\end{array}$ & $\begin{array}{c}\text { Detectable ETA } \\
\text { serum level } \\
(\mathbf{n}=\mathbf{3 0})\end{array}$ & $\begin{array}{c}\text { Undetectable } \\
\text { ETA serum level } \\
(\mathbf{n}=\mathbf{2})\end{array}$ & $\mathbf{P}$ \\
\hline BASDAI & $1.35 \pm 0.9$ & $1.85 \pm 0.9$ & 0.86 \\
\hline ASDAS-CRP & $1.5 \pm 0.7$ & $2.42 \pm 0.9$ & 0.68 \\
\hline ASDAS-ESR & $1.44 \pm 0.6$ & $2.33 \pm 0.7$ & 0.79 \\
\hline CRP $(\mathrm{mg} / \mathrm{l})$ & $8.13 \pm 11.6$ & $24.7 \pm 17.5$ & 0.42 \\
\hline ESR $(\mathrm{mm} / \mathrm{h})$ & $15.6 \pm 16.5$ & $37 \pm 9.8$ & 0.65 \\
\hline
\end{tabular}


Interestingly, drug serum level correlated to ASDAS-CRP $(\mathrm{r}=-0.432, \mathrm{P}=0.01)$ but not to ASDASESR $(r=-0.266, P=0.141)$ or BASDAI $(r=-0.253$, $\mathrm{P}=0.16)$.

No anti-etanercept antibodies were found when performing the ELISA determination.

No adverse event was recorded in the ETA-treated group.

Thirty-three percent of patients in the present study were on IFX. Detectable IFX serum level was identified in $60 \%$. Patients with undetectable IFX drug level had significantly higher ESR $(\mathrm{P}<0.001)$ and $\mathrm{CRP}(\mathrm{P}=0.03)$ and higher disease activity scores (BASDAI, $\mathrm{P}=0.02$, ASDAS-ESR, $\mathrm{P}<0.001$ and ASDAS-CRP, $\mathrm{P}<0.001)$.

Anti-IFX antibodies tested positive in $48 \%$ of patients, with significantly higher disease activity scores (BASDAI $\mathrm{P}=0.002$, ASDAS-ESR $\mathrm{P}=0.01$ and ASDAS-CRP $\mathrm{P}=0.01$ ).

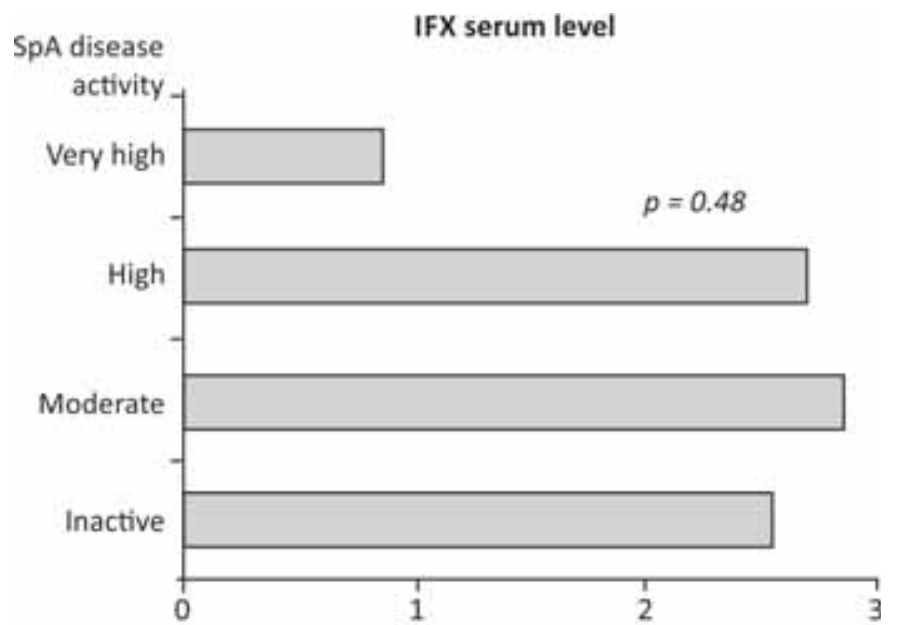

FIGURE 6. IFX serum level in respect to disease activity categories, according to ASDAS-CRP
The quantitative measure of IFX serum determination is seen below in Fig. 6, with no significant inter-group differences $(\mathrm{P}=0.48)$.

The association between drug serum level and disease activity, monitored by conventional scores (BASDAI and ASDAS) led us to categorize patients according to their disease status. For theoretical purpose, Fig. 7 illustrates overall drug serum level in responder versus non-responder patients, according to an ASDAS-CRP cut-off of 3.5.

As seen on the left in Fig. 8, we detailed drug serum level for each anti-TNF product respecting ASDAS-CRP distribution. For a score lower than 2.1 which signifies inactive or moderate disease activity, drug level is situated between 2 and $4 \mu \mathrm{g} / \mathrm{mL}$, indicating this value as target in treating SpA patients.

Further, we similarly illustrated (Fig. 9) drug serum level according to BASDAI value differentia-

$\square$ IfX serum level $(\mu \mathrm{g} / \mathrm{mL})$

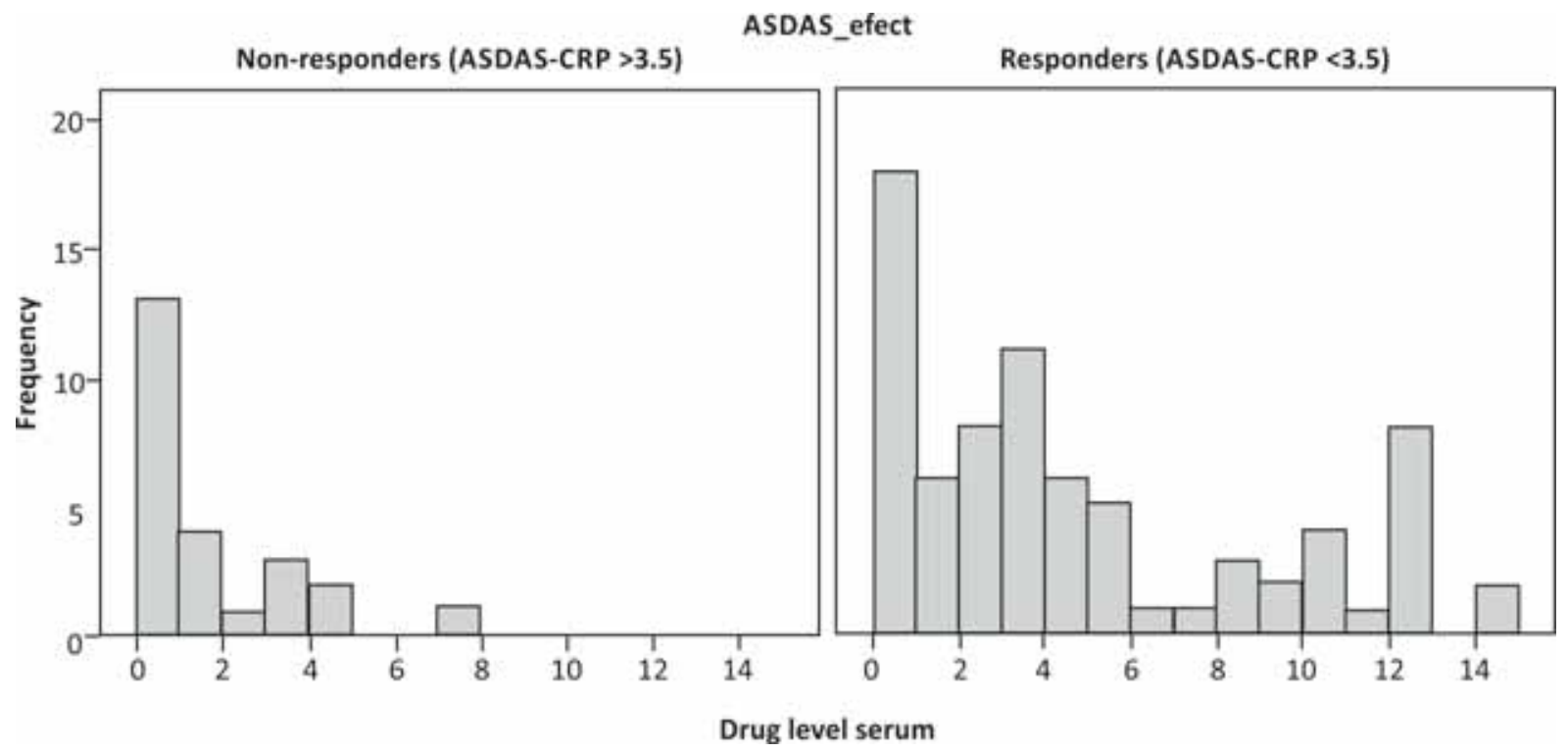

FIGURE 7. Drug serum level distribution in responder versus non-responder patients, according to $A S D A S-C R P(P<0.001)$ 




FIGURE 8.

BASDAI_efect

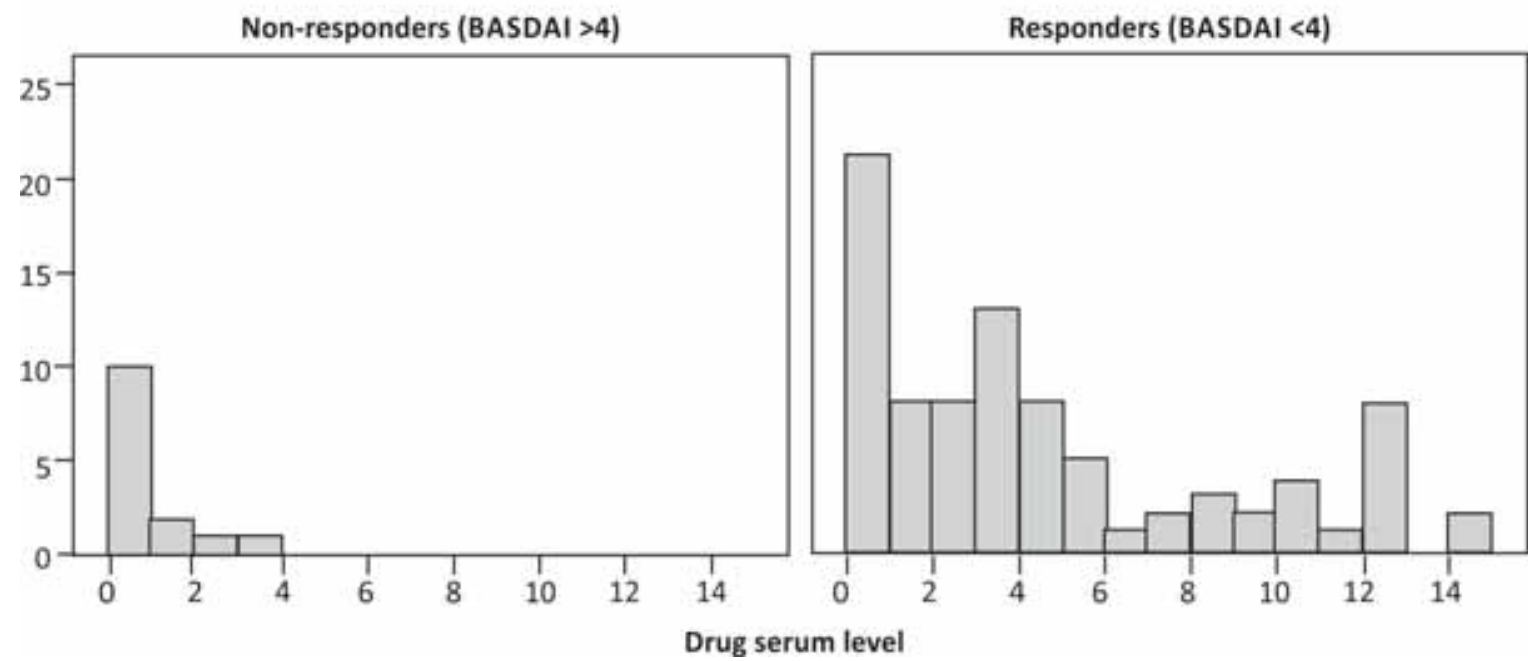

FIGURE 9. Drug serum level distribution in responder versus non-responder patients, according to BASDAI $(P<0.001)$ 
tion (BASDAI over 4 represents non-responder patients and BASDAI below 4 is for responders).

Regarding drug survival in the study lot, mean persistence was 45.6 months \pm 26.5 , as seen below in Fig. 10. Naïve patients have a treatment persistence of 48.4 months while patients who benefited from a switch followed treatment for 31.6 months $(\mathrm{P}=$ $0.015)$.

Out of the 17 patients that went through at least one therapeutical switch, $14(82 \%)$ were attributed to loss of efficacy after more than 3 months, thus classifying them as secondary non-responders. Nevertheless, we cannot assess the percentage of those who had positive anti-drug antibodies therefore the decision was purely based on the clinician's judgement. Other justifications for change of therapy were allergic reactions, tuberculosis infection or unspecified (1 patient).

There are no significant differences in drug serum level in naïve patients versus those who previously switched products.

\section{DISCUSSIONS}

The present study aimed to evaluate the immunogenic profile of anti-TNF agents (ADL, ETA, IFX) in patients with $\mathrm{SpA}$ and to assess a cut-off value of the drug that can represent a therapeutic target in these patients.

There is still no clear updated consensus as to whether drug serum level monitoring and anti-drug antibody detection might represent useful tools in clinical practice in assessing disease activity in pa-

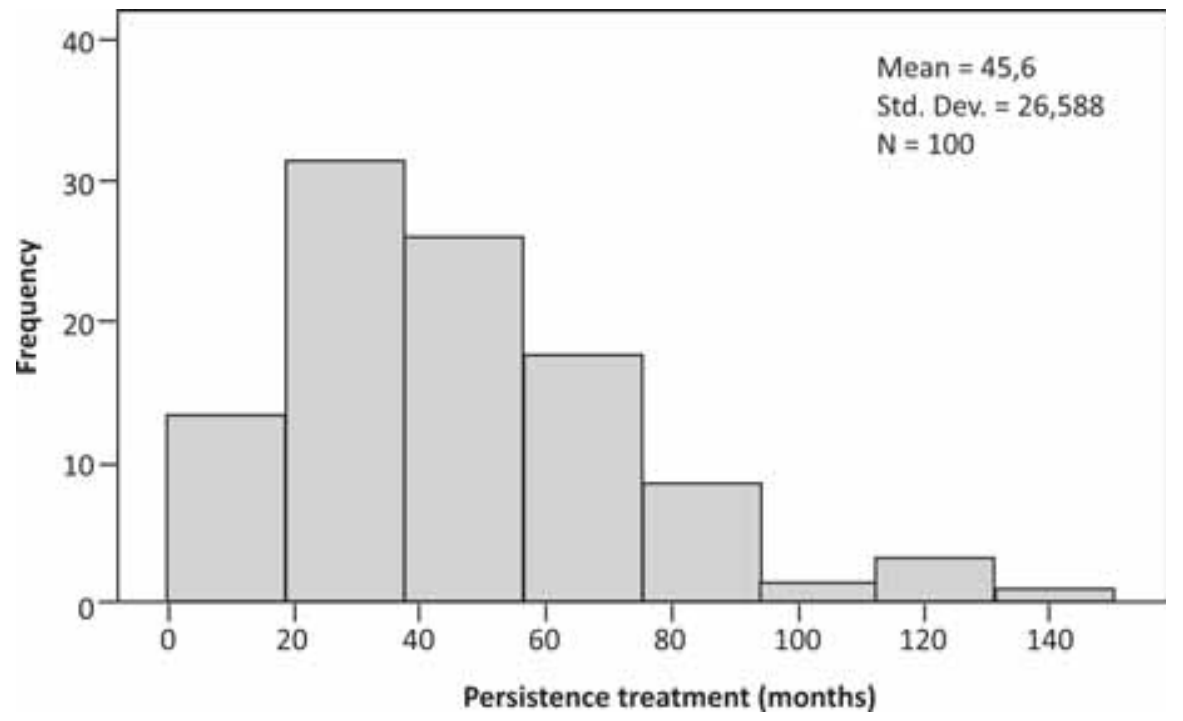

FIGURE 10. Mean drug persistence in the study cohort

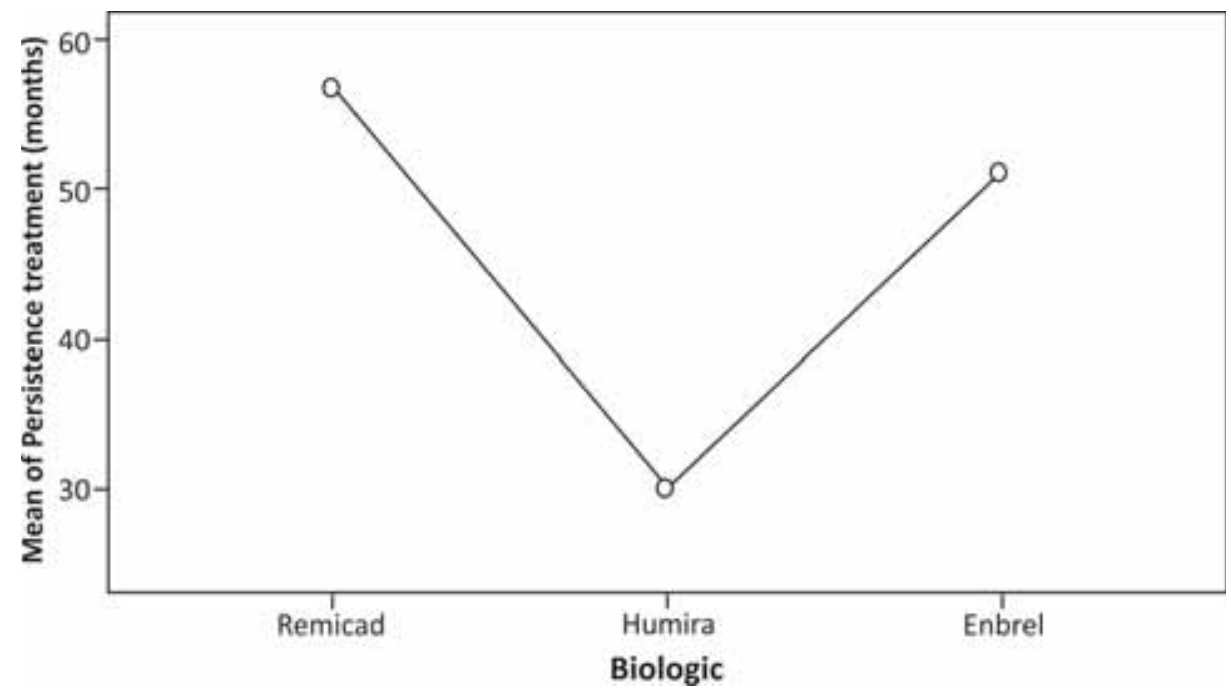

FIGURE 11. Shows individualized biologic persistence and we notice $A D L$ as having the lowest survival period of 29.9 months. 
tients with spondyloarthritis under anti-TNF therapy (15-17). Studies on anti-TNFs indicate a higher failure occurrence rate in patients testing positive for anti-drug antibodies, suggesting that their development is the reason behind patients' non-responsiveness $(18,19)$. However other publications found no relationship between response to therapy and the presence of anti-drug antibodies suggesting that this determination is not clinically relevant or helpful in patient assessment (20). These controversial results might be due to the detection method which is not standardized or the timing of the sample collection (21). Moreover the positivity rate of anti-drug antibodies varies among studies and is estimated at $25 \%$ for SpA patients $(22,23)$, similarly to rheumatoid arthritis patients (33\%) (10).

It is relatively widely accepted that drug serum level correlates to disease activity $(24,25)$. We obtained interesting results in ADL-treated patients concerning drug serum level that was lower in patients with increased disease activity, therefore reflecting the underlying cause of non-response. ADL serum level has a relatively descending trend in patients with very high activity. Thus we share opinions of experts that rank this kind of determination as important in assessing patient disease activity (26,27).

Regarding the ETA study group there were only two patients from the entire study cohort that had no detectable drug serum, therefore we were limited to draw pertinent conclusions. We raise the issue of an adjacent mechanism that makes this type of patients to require a more frequent ETA administration taking into account that no anti-drug antibodies were found when tested. We ruled out medication nonadherence in these patients.

ETA is a fusion protein that consists of human TNF receptor and the Fc structure of human IgG. Trials that have identified anti-ETA antibodies confirm that they are non-neutralizing, thus they do not interfere with the drug's safety or efficacy. However,

\section{REFERENCES}

1. Maneiro J.R., Souto A., Salgado E., Mera A., Gomez-Reino J.J. Predictors of response to TNF antagonists in patients with ankylosing spondylitis and psoriatic arthritis: systematic review and metaanalysis. RMD Open. 2015; 1(1):e000017-e000017. doi:10.1136/ rmdopen-2014-000017.

2. Svenson M., Geborek P., Saxne T., Bendtzen K. Monitoring patients treated with anti-TNF-alpha biopharmaceuticals: assessing serum infliximab and anti-infliximab antibodies. Rheumatology (Oxford). 2007;46(12):1828-1834. doi:10.1093/rheumatology/ kem261. most studies did not detect anti-ETA antibodies when performing ELISA procedures. As expected, no antibodies were detected in this study which stands in accordance with most data published in the literature that state that ETA has the lowest immunogenicity amongst anti-TNF agents $(28,29)$.

Drug serum level in patients treated with IFX did not differ significantly between groups of disease activity.

There are certain limitations of the study that are linked to the relatively small number of patients that had a unique blood sampling for drug serum level determination and anti-drug antibodies detection. Furthermore, the ELISA technique that we used in the study is not capable of identifying immunocomplexes formed between the biologic drug and antidrug antibodies.

The present study showed an estimated cut-off value situated between 2 and $4 \mu \mathrm{g} / \mathrm{mL}$ of active substance that could insure patients with a moderate or inactive disease, according to ASDAS-CRP. However, comparison between the three TNF inhibitors is strictly theoretical and requires further studies in order to establish valid cut-offs that can indicate if patients have therapeutic or subtherapeutic levels of active substance.

\section{CONCLUSIONS}

In the present study we obtained a good correlation between drug serum level, anti-drug antibodies and disease activity. In patients with SpA on antiTNF therapy, low drug concentrations and the presence of anti-drug antibodies are highly indicative of the patients' disease activity and confirm results of disease activity scores. In accordance with other studies, we recommend including this detection in the regular clinical practice, at the very base of the therapeutic approach. The rational course would be to firstly determine drug concentration and only if this is absent or at a minimal value should we pursue with antibody detection.
3. Bartelds G.M. Development of Antidrug Antibodies Against Adalimumab and Association With Disease Activity and Treatment Failure During Long-term Follow-up. JAMA. 2011; 305(14):1460. doi:10.1001/jama.2011.406.

4. Wolbink G.J., Vis M., Lems W., et al. Development of antiinfliximab antibodies and relationship to clinical response in patients with rheumatoid arthritis. Arthritis Rheum. 2006; 54(3):711-715. doi:10.1002/art.21671.

5. Jani M., Chinoy H., Warren R.B., et al. Clinical utility of random anti-TNF drug level testing and measurement of anti-drug 
antibodies on long-term treatment response in rheumatoid arthritis. Arthritis Rheumatol. 2015; 67(8):n/a - n/a. doi:10.1002/art.39169.

6. Kneepkens E.L., Wei JC-C., Nurmohamed M.T., et al. Immunogenicity, adalimumab levels and clinical response in ankylosing spondylitis patients during 24 weeks of followup. Ann Rheum Dis. 2015; 74(2):396-401. doi:10.1136/ annrheumdis-2013-204185.

7. Kneepkens E.L., Krieckaert C.L.M., van der Kleij D., et al. Lower etanercept levels are associated with high disease activity in ankylosing spondylitis patients at 24 weeks of followup. Ann Rheum Dis. 2015; 74(10):1825-1829. doi:10.1136/ annrheumdis-2014-205213.

8. Paccou J., Solau-Gervais E., Houvenagel E., et al. Efficacy in current practice of switching between anti-tumour necrosis factor- $\alpha$ agents in spondyloarthropathies. Rheumatology (Oxford). 2011; 50(4):714-720. doi:10.1093/rheumatology/keq377

9. Afif W., Loftus E.V., Faubion W.A., et al. Clinical utility of measuring infliximab and human anti-chimeric antibody concentrations in patients with inflammatory bowel disease. $A m \mathrm{~J}$ Gastroenterol. 2010; 105(5):1133-1139. doi:10.1038/ajg.2010.9.

10. Mazilu D., Opriş D., Gainaru C., et al. Monitoring drug and antidrug levels: a rational approach in rheumatoid arthritis patients treated with biologic agents who experience inadequate response while being on a stable biologic treatment. Biomed Res Int. 2014; 2014:702701. doi:10.1155/2014/702701.

11. Vincent F.B., Morand E.F., Murphy K., Mackay F., Mariette X., Marcelli C. Antidrug antibodies (ADAb) to tumour necrosis factor (TNF)-specific neutralising agents in chronic inflammatory diseases: a real issue, a clinical perspective. Ann Rheum Dis. 2013; 72(2):165-178. doi:10.1136/annrheumdis-2012-202545.

12. Garcês S., Demengeot J., Benito-Garcia E. The immunogenicity of anti-TNF therapy in immune-mediated inflammatory diseases: a systematic review of the literature with a meta-analysis. Ann Rheum Dis. 2013; 72(12):1947-1955. doi:10.1136/ annrheumdis-2012-202220.

13. Kroon F.P., van der Burg L.R., Ramiro S., et al. Nonsteroidal anti-inflammatory drugs (NSAIDs) for axial spondyloarthritis (ankylosing spondylitis and non-radiographic axial spondyloarthritis). Cochrane database Syst Rev. 2015; 7:CD010952. doi:10.1002/14651858.CD010952.pub2.

14. Guellec D., Nocturne G., Tatar Z., et al. Should non-steroidal anti-inflammatory drugs be used continuously in ankylosing spondylitis? Joint Bone Spine. 2014; 81(4):308-312. doi:10.1016/j. jbspin.2014.01.003.

15. De Vries M.K., Wolbink G.J., Stapel S.O., et al. Decreased clinical response to infliximab in ankylosing spondylitis is correlated with anti-infliximab formation. Ann Rheum Dis. 2007; 66(9):1252-1254. doi:10.1136/ard.2007.072397.

16. Bartelds G.M. Development of Antidrug Antibodies Against Adalimumab and Association With Disease Activity and Treatment Failure During Long-term Follow-up. JAMA. 2011; 305(14):1460. doi:10.1001/jama.2011.406.

17. De Vries M.K., Brouwer E., van der Horst-Bruinsma I.E., et al. Decreased clinical response to adalimumab in ankylosing spondylitis is associated with antibody formation. Ann Rheum Dis. 2009; 68(11):1787-1788. doi:10.1136/ard.2009.109702.
18. Van der Maas A., van den Bemt B.J.F., Wolbink G., van den Hoogen F.H.J., van Riel P.L.C.M., den Broeder A.A. Low infliximab serum trough levels and anti-infliximab antibodies are prevalent in rheumatoid arthritis patients treated with infliximab in daily clinical practice: results of an observational cohort study. BMC Musculoskelet Disord. 2012; 13(1):184. doi:10.1186/1471-247413-184.

19. Paramarta J.E., Baeten D.L. Adalimumab serum levels and antidrug antibodies towards adalimumab in peripheral spondyloarthritis: no association with clinical response to treatment or with disease relapse upon treatment discontinuation. Arthritis Res Ther. 2014; 16(4):R160. doi:10.1186/ar4675.

20. Krieckaert C.L.M., Lems W.F. Are we ready for therapeutic drug monitoring of biologic therapeutics? Arthritis Res Ther. 2011; 13(4):120. doi:10.1186/ar3395.

21. Hock B.D., Stamp L.K., Hayman M.W., Keating P.E., Helms E.T.J., Barclay M.L. Development of an ELISA based competitive binding assay for the analysis of drug concentration and anti-drug antibody levels in patients receiving adalimumab or infliximab. Ther Drug Monit. July 2015. doi:10.1097/FTD.0000000000000229.

22. Krzysiek R., Breban M., Ravaud P., et al. Circulating concentration of infliximab and response to treatment in ankylosing spondylitis: results from a randomized control study. Arthritis Rheum. 2009; 61(5):569-576. doi:10.1002/art.24275.

23. Maneiro J.R., Salgado E., Gomez-Reino J.J. Immunogenicity of monoclonal antibodies against tumor necrosis factor used in chronic immune-mediated Inflammatory conditions: systematic review and meta-analysis. JAMA Intern Med. 2013; 173(15):14161428. doi:10.1001/jamainternmed.2013.7430.

24. Mok C.C., van der Kleij D., Wolbink G.J. Drug levels, anti-drug antibodies, and clinical efficacy of the anti-TNFa biologics in rheumatic diseases. Clin Rheumatol. 2013; 32(10):1429-1435. doi:10.1007/s10067-013-2336-x.

25. Anderson P.J. Tumor necrosis factor inhibitors: clinical implications of their different immunogenicity profiles. Semin Arthritis Rheum. 2005; 34(5 Suppl1):19-22. doi:10.1016/j.semarthrit.2005.01.005.

26. Lorenzin M., Ortolan A., de Hooge M., et al. Lengthening the time intervals between doses of biological agents in psoriatic arthritis patients: A single-center retrospective study. Int J Immunopathol Pharmacol. 2015;28(4):479-487. doi:10.1177/0394632015599446.

27. Vogelzang E.H., Kneepkens E.L., Nurmohamed M.T., et al. Antiadalimumab antibodies and adalimumab concentrations in psoriatic arthritis; an association with disease activity at 28 and 52 weeks of follow-up. Ann Rheum Dis. 2014; 73(12):2178-2182. doi:10.1136/ annrheumdis-2014-205554.

28. Arstikyte I., Kapleryte G., Butrimiene I., Venalis A. Influence of Immunogenicity on the Efficacy of Long-Term Treatment with TNF a Blockers in Rheumatoid Arthritis and Spondyloarthritis Patients. Biomed Res Int. 2015; 2015:604872. doi:10.1155/2015/604872.

29. Thomas S.S., Borazan N., Barroso N., et al. Comparative Immunogenicity of TNF Inhibitors: Impact on Clinical Efficacy and Tolerability in the Management of Autoimmune Diseases. A Systematic Review and Meta-Analysis. BioDrugs. 2015; 29(4):241258. doi:10.1007/s40259-015-0134-5. 